\title{
El derecho de retracto
}

Fernando Vidal RamíreZ

Abogado por la Universidad Nacional Mayor de San Marcos. Miembro de la Comisión de las Naciones Unidas para el Derecho Mercantil Internacional.

Miembro del Consejo Consultivo del INDECOPI.

Presidente de la Comisión Consultiva de Justicia.

Ex Decano del Colegio de Abogados de Lima.

Ex presidente de la Federación Iberoamericana de Bolsas de Valores.

Ex presidente de la Bolsa de Valores de Lima. Juez Ad Hoc en la Corte Interamericana de Derechos Humanos.

SUMARIO:

I. Premisa.

II. El retracto en la codificación civil.

III. El derecho de retracto.

1. Su noción.

2. Caracteres.

3. Su ejercicio.

4. El plazo para su ejercicio.

5. La vía procedimental. 


\title{
RESUMEN:
}

El presente artículo tiene como objeto el derecho de retracto en el civil law. Para esto se comienza con la historia del derecho de retracto en la codificación civil global y peruana para luego adentrarse en los casos y requisitos para que este derecho pueda ser ejercido.

Palabras clave: Derecho de retracto, derecho civil, enajenación.

\begin{abstract}
:
In the following article, the right of first refusal in the civil law system is discussed. The article starts with the history of this right in global and peruvian civil codification and then moves onto the cases and requirements for this right to be exercised.

Keywords: Right of first refusal, civil law, dispossession
\end{abstract}

\section{PREMISA}

En el ensayo que vamos a desarrollar, vamos a considerar el derecho de retracto como derecho subjetivo, es decir, como la facultad, poder o prerrogativa que confiere el Código Civil a un tercero respecto a la relación contractual de un vendedor y un comprador, o respecto a la de un acreedor a quien su deudor le adjudica un bien con la finalidad de extinguir su obligación. El tercero, por una situación determinada en la que se encuentra, mediante el retracto se subroga al comprador o al adjudicatario del bien, asumiendo su posición y las estipulaciones del contrato o las convenidas en la dación en pago.

El retracto es una institución jurídica normada de manera característica por nuestro Código Civil, como un apéndice al contrato de compraventa, no obstante que también procede en la dación en pago; pues, en ambos casos, por el retracto el que lo ejercita se sustituye al comprador del bien o al acreedor a quien se le adjudica un bien en pago.

\section{EL RETRACTO EN LA CODIFICACIÓN CIVIL}

El retracto no tuvo arraigo en el Derecho Romaen los ordenamientos jurídicos de la Europa
Medieval; aunque, como anota Arias Schreiber' ${ }^{1}$, fue utilizado para mantener la concentración territorial y evitar que la propiedad familiar pasara a ser propiedad de extraños mediante el denominado retracto gentilicio. Posteriormente, como consecuencia de la Revolución Francesa, el retracto fue siendo relegado, lo que determinó un tratamiento legislativo disímil en la sistematización del Derecho Civil y su codificación, como ocurre en el Código Civil francés vigente desde 1804, en el Código Civil alemán vigente desde 1900 y en el Código Civil italiano de 1942, que constituyen los tres grandes hitos en la historia de la codificación civil por su poderosa influencia en la codificación civil posterior a su respectiva vigencia.

El Código Civil francés de 1804, el denominado Código Napoleón, de decisiva influencia en la codificación del siglo XIX y aún en la del siglo $\mathrm{XX}$, no sistematizó el tratamiento del retracto, pues lo legisló para situaciones específicas, como el retracto entre los sucesores - artículo 841 - y el retracto entre litigantes —artículo 1699-.

El Código Civil alemán, el denominado BGB -Bürgerliches Gesetzbuch-, vigente desde 1900, de decisiva influencia durante la primera mitad del siglo XX, no legisla propiamente sobre el retracto con el significado que tiene en

1. ARIAS SCHREIBER PEZET, Max. Exégesis del Código Civil peruano de 1984. Tomo II. Lima: San Jerónimo, 1988. 
nuestra codificación civil, pues lo legisla como convenio de recompra —artículo 491—22.

El Código Civil italiano, vigente desde 1942, de decisiva influencia en la codificación civil durante la segunda mitad del siglo $X X$, de la que no ha sido ajeno nuestro Código Civil vigente desde 1984, lo legisla en el articulado del contrato de venta como retracto convencional, como un pacto especial, según el cual el vendedor puede reservarse el derecho de adquirir de nuevo la propiedad de la cosa vendida mediante la restitución del precio y otros reembolsos — artículo 1500 - . La doctrina italiana le da el nombre de pacto de rescate ${ }^{3}$.

La codificación civil peruana le ha dado al retracto un tratamiento legislativo distinto al Código Civil francés, pues lo sistematizó y, respecto a los Códigos Civiles alemán e italiano, lo distinguió de los pactos de recompra y de rescate, a los que resume en el pacto de retroventa como ocurrió con el Código Civil de 1852, el Código Civil de 1936 y ocurre en el vigente de 1984 , considerando al retracto como una institución jurídica con normatividad propia de la que emana el derecho de retracto.

El Código Civil de 1852, si bien recibió influencia napoleónica, no legisló el retracto en forma aislada y para casos específicos, sino que lo sistematizó bajo un epígrafe especial dentro del Título correspondiente al Contrato de Compraventa. Raoul de la Grassier en su Juicio Crítico consideró que el retracto estaba rigurosamente organizado, como en el Ancien Droit, en tanto que el actual Derecho Francés no lo admitía sino en el caso de cesión de derechos litigio$\operatorname{sos}^{4}$. De este modo, el Código Civil del siglo XIX marcó la pauta para la codificación civil peruana posterior.

El Código Civil de 1936, promulgado cuando ya el BGB irradiaba su influencia, fue consecuente con los cambios experimentados en la sociedad peruana y receptó la evolución de nuestro Derecho Civil. Pretendió ser un código técnico y en alguna medida lo fue, disminuyendo su articulado y evitando dar contenido a definiciones en sus normas. Tomando la pauta del Código Civil de 1852 , se legisló sobre el retracto en el articulado correspondiente al Título de la Compraventa disminuyendo a los titulares del ejercicio del derecho de retracto, al no considerar, obviamente, las situaciones jurídicas vinculadas a instituciones que habían sido abolidas, como es el caso de los censos, enfiteusis, capellanías y otras.

En el Código Civil vigente desde 1984, no obstante la influencia ejercida por el Código Civil italiano de 1942, ha mantenido el tratamiento legislativo del retracto en un capítulo comprendido en el Título de la Compraventa. Al respecto, el tratamiento del retracto y su naturaleza jurídica fue objeto de diversas opiniones durante el proceso de reforma del Código Civil de 1936 que concluyó con la promulgación del actual Código Civil ${ }^{5}$.

\section{EL DERECHO DE RETRACTO}

\section{Su noción.}

Como lo hemos advertido en la premisa, vamos a considerar el derecho de retracto como derecho subjetivo porque, en efecto, lo es; pero con una característica sui generis en cuanto que es concedido —en este caso por el Código Civil-

2. Cfr. La aclaración que hace el editor del Código Alemán publicado como apéndice del Tratado de Derecho Civil de Ennecerus, Kipp y Wolff, página 101, en el sentido de que el vocablo alemán Wiederkauf significa "retracto", pero solo convencional, es decir, como el derecho del vendedor de comprar al comprador lo que él antes le ha vendido.

3. MESSINEO, Francesco. Manual de Derecho Civily Comercial. Tomo V, Buenos Aires: EJEA, 1979 p. 68.

4. LAMA, Miguel Antonio. Código Civil. Anotado y Concordado. Lima: Librería e Imprenta Gil, 1906, p. XXXVII.

5. CASTILLO FREYRE, Mario. Tratado de la Venta. Tomo V. Lima: Fondo Editorial de la Pontificia Universidad Católica del Perú, 2000, p. 261. 
cuando el sujeto se encuentra en una situación jurídica por la que le corresponde su ejercicio, pero con las limitaciones que el mismo Código Civil le impone.

El Código Civil ha previsto el ejercicio del derecho de retracto en los casos de un contrato de compraventa - artículo 1592-y de dación en pago - artículo 1593 - que son actos enajenativos a título oneroso. Sin embargo, el Código Civil no ha previsto ni dispuesto que proceda también en la permuta - que es también un acto enajenativo y oneroso- ni en otros actos jurídicos, en los que considero que hacen ejercitable el derecho de retracto cuando la enajenación es a título oneroso, debiéndose invocar para ello la analogía; mas no, por ejemplo, en la donación, en la que la enajenación es a título gratuito.

El artículo 1592 del Código Civil conceptúa el derecho de retracto en relación con el contrato de compraventa como "el que la ley otorga a determinadas personas para subrogarse en lugar del comprador y en todas las estipulaciones del contrato de compraventa" y agrega que "el retrayente debe reembolsar al adquirente el precio, los tributos y gastos pagados por éste y, en su caso, los intereses pactados". Si el precio ha sido pactado para pagarse a plazos, el artículo 1598 dispone que "es obligatorio el otorgamiento de una garantía para el pago del precio pendiente, aunque en el contrato que da lugar al retracto no se hubiera convenido". Y, si el mismo bien ha sido materia de dos o más enajenaciones, el artículo 1601 dispone que el derecho de retracto puede ser ejercitado con relación a la primera enajenación pagándose el precio, tributos gastos e intereses, quedando sin efecto la otra u otras enajenaciones.

\section{Caracteres.}

Como puede apreciarse por lo anteriormente expuesto, siendo el derecho de retracto un derecho subjetivo, le incumbe también el cum- plimiento de un deber jurídico, esto es, de una obligación, pues el retrayente al subrogarse al comprador se obliga a pagar el precio al vendedor y sus accesorios $y$, al subrogarse al deudor en una dación en pago, se obliga a pagarle al acreedor el monto de la deuda.

El artículo 1595 del Código Civil le atribuye al derecho de retracto el carácter de ser irrenunciable e intransmisible por acto entre vivos, constituyéndose en norma de orden público por su finalidad prohibitiva. El ejercicio del derecho de retracto es voluntario, por lo que la prohibición de renunciarlo debe entenderse cuando se trata de una renuncia mediante manifestación de voluntad expresa, porque el no ejercicio del derecho constituye una renuncia tácita, conforme a la doctrina informante del artículo 1041 del Código Civil. La prohibición de transmisibilidad está limitada a que se realice mediante acto entre vivos, porque la transmisibilidad si opera por acto mortis causa, siempre que el sucesor asuma la misma situación jurídica en la que se encontraba su causante por ser esta situación a la que el Código Civil confiere el derecho de retracto.

Atendiendo a lo expuesto, el derecho de retracto es un derecho intuito personae, esto es, personalísimo, como lo califica el maestro León Barandiarán, pues solo es ejercitable por quien le es concedido por el Código Civil por encontrarse en la posición prevista en su artículo $1599^{6}$.

\section{Su ejercicio.}

El Código Civil confiere el derecho de retracto a quienes se encuentren en la situación jurídica taxativamente enumerada por el artículo 1599 y declara que procede, según su artículo 1594, en los casos de enajenación voluntaria de bienes muebles inscritos y de inmuebles.

En primer lugar, goza del derecho de retracto el copropietario en caso de la venta a un tercero de las porciones indivisas - numeral 2-,

6. LEÓN BARANDIARÁN, José. Tratado de Derecho Civil. Tomo V. Lima: WG Editores, p. 135. 
esto es, cuando un bien pertenece a dos o más personas y no se ha procedido a su partición y se le mantiene indiviso teniendo cada propietario su correspondiente cuota ideal y ésta es la que se vende.

En segundo lugar, goza del derecho de retracto el litigante, en caso de venta por el contrario del bien que se está discutiendo judicialmente -numeral 3-.

En tercer lugar, el propietario, en la venta del usufructo y a la inversa, en caso de que el usufructuario esté transfiriendo su derecho - numeral 4-. Como se sabe, el usufructo es la facultad de usar y disfrutar de un bien otorgado por quien está legitimado para otorgarla por contrato o acto jurídico por el plazo estipulado.

En cuarto lugar, el propietario del suelo y el superficiario, en la venta de sus respectivos derechos -numeral 5-. Como se sabe, el derecho de superficie se constituye por el propietario del suelo para que el superficiario levante una construcción en propiedad separada del suelo por el plazo que se estipule, a cuyo vencimiento lo construido revierte el favor del propietario del suelo.

En quinto lugar, los propietarios de predios urbanos divididos materialmente en partes y que no pueden ejercitar sus derechos sin someter las demás partes del bien a servidumbres o a servicios que disminuyan su valor - numeral 6-. La redacción es confusa, pero León Barandiarán la explica precisando que no es un caso de condominio y que su finalidad es hacer desaparecer la servidumbre u otro servicio mediante el retracto que puede ejercitar el propietario gravado con la servidumbre en caso de la venta de la parte del predio en cuyo favor se ha constituido la servidumbre?.

En sexto lugar, el propietario de la tierra colindante, cuando se trate de la venta de una finca rústica cuya cabida no exceda de la unidad agrícola o ganadera mínima respectiva, o cuando aquella y ésta reunidas no excedan de dicha unidad -numeral 7-, sin que se haya precisado la dimensión de la unidad agrícola o ganadera, por lo que ha debido mantener la fórmula que adoptó el Código Civil de 1936, que atribuía a la finca rústica una cabida de 3 hectáreas, y que al retraerse por el dueño del terreno colindante ambas no excedieran de 10 hectáreas. El retracto, en este caso, considero que es un rezago de la Reforma Agraria realizada durante el Gobierno del General Velasco. Según Arias Schreiber este retracto no tiene cabida en el Código Civil ${ }^{8}$.

Como ya hemos advertido, la enumeración de los legitimados para ejercitar el derecho de retracto es taxativa y determina el orden de prelación en caso concurran dos o más retrayentes, pues así lo dispone el artículo 1600 del Código Civil.

El ejercicio del derecho de retracto no procede en las ventas por remate público - artículo 1592 , in fine-.

\section{El plazo para su ejercicio.}

El plazo para el ejercicio del derecho de retracto es de 30 días computados a partir de la fecha en que su titular toma conocimiento del contrato o acto jurídico enajenativo a título oneroso. El plazo es de caducidad porque a su vencimiento el derecho de retracto queda extinguido.

El plazo de 30 días lo establece el artículo 1596 del Código Civil contados desde la comunicación de fecha cierta a la persona que goza del derecho de retracto. Esta viene a ser la regla general. Sin embargo, el mismo artículo 1596 y el artículo 1597 establecen circunstancias que no le hacen perder el ejercicio de su derecho al retrayente.

7. Ibíd., p.143.

8. ARIAS SCHREIBER PEZET, Max. Op. Cit., p. 141. 
La primera es que los celebrantes del acto enajenativo no tengan conocimiento del domicilio de quien goza del derecho de retracto, por lo que pueden darle publicidad al acto en el diario encargado de los avisos judiciales y en otro de mayor circulación en la localidad por tres veces con intervalo de cinco días entre cada aviso. En este caso, precisa el artículo 1596, el plazo de 30 días se cuenta desde el día siguiente al de la última publicación.

Al respecto, consideramos conveniente dejar establecido que el plazo corre contra el titular del derecho de retracto en razón de que el artículo 1596 no es imperativo para los celebrantes del acto enajenativo, pues pueden no comunicarlo al posible retrayente ni hacer la publicación. La omisión no afecta la validez del acto y explica la disposición del artículo 1597.

En efecto, si el retrayente conoce de la transferencia de los bienes - muebles inscritos o inmuebles - por cualquier otro medio, el plazo de 30 días se computa a partir de la fecha en que tomó ese conocimiento. Si el conocimiento lo tomó por la inscripción del bien transferido en los Registros Públicos, para este caso, pre- cisa el artículo 1597, el principio de la publicidad registral, que establece el artículo 2012 del Código Civil, solo le es oponible al retrayente transcurrido un año de la inscripción de la transferencia.

Como se sabe, el principio de la publicidad registral presume, con presunción jure et de jure, que toda persona tiene conocimiento del contenido de las inscripciones. Sin embargo, este principio cede ante el derecho de retracto, pues le es inoponible durante el primer año de la inscripción de los bienes enajenados y es durante ese primer año que corre el plazo de 30 días para ejercitarlo.

\section{La vía procedimental.}

El ejercicio del derecho de retracto conlleva la carga de la prueba -onus probandi incumbit actori-, pues el retrayente tiene que demostrar que está en el goce del derecho y que lo está ejercitando dentro del plazo.

La tramitación del ejercicio del derecho de retracto está normada por el Código Procesal Civil mediante el procedimiento del proceso abreviado. 